\section{Intravitreal triamcinolone as a primary therapy in diabetic macular oedema}

M Karacorlu' ${ }^{1}$, H Ozdemir ${ }^{1}$, S Karacorlu' ${ }^{1}$, N Alacali², B Mudun ${ }^{3}$ and E Burumcek ${ }^{3}$
${ }^{1}$ Istanbul Retina Institute Istanbul, Turkey

${ }^{2}$ Turkish Diabetes Foundation Hospital Istanbul, Turkey

\section{${ }^{3}$ SSK Okmeydani Hospital} Department of Ophthalmology, Okmeydani Turkey

Correspondence:

M Karacorlu Istanbul Retina Institute Hakki Yeten Cad. No: 8, Kat: 7, 34349 Fulya Istanbul, Turkey Tel: + 902122313121 Fax: + 902122332425 E-mail: retina@ pobox.com

Received: 17 November 2003

Accepted in revised form: 9 February 2004 Published online: 13 August 2004

The authors have no proprietary interest in the material used in this study.

\begin{abstract}
Purpose To evaluate the effect of intravitreal triamcinolone in eyes with diabetic macular oedema that had no previous laser treatment. Methods In all, 12 eyes of 12 patients with diabetic retinopathy, aged 47-70 years (mean 59.2), made up the study. All the eyes had persistent diabetic macular oedema despite having received medical treatment for at least 3 months. In this consecutive case series, none of the eyes received previous laser photocoagulation. Intravitreal injection of $0.1 \mathrm{ml}(4 \mathrm{mg})$ triamcinolone acetonide was offered to treat macular oedema. The visual and anatomic responses were observed as well as complications related to the injection procedure and corticosteroid medication. Results The follow-up period was between 6 and 10 months (mean 7.9 months) and all eyes completed 6 months of follow-up. Macular oedema was documented for an average of 3.5 months (ranged 3-5 months) before intravitreal corticosteroid injection. Baseline mean central macular thickness was $448.6 \mu \mathrm{m}$. At 1 month follow-up, a reduction in mean central macular thickness of $40.8 \%$ from $448.6 \mu \mathrm{m}$ to $265.4 \mu \mathrm{m}$ was obtained. At 3 and 6 months follow-up, mean central macular thicknesses, were $310 \mu \mathrm{m}$ and $294.5 \mu \mathrm{m}$, respectively. No eyes lost vision at 1 month and 10 eyes (83.2\%) showed improvement. At 3 months, no eyes lost vision from baseline and 8 eyes $(66.6 \%)$ showed improvement. At 6 months, again no eyes lost vision from baseline and 10 eyes $(83.2 \%)$ maintained improved visual acuity.

Conclusions Intravitreal triamcinolone is a promising therapeutic method in eyes with diabetic macular oedema without previous application of laser treatment. Further study with longer follow-up and large series is
\end{abstract}

warranted to assess the long-term efficacy and safety and the need for retreatment.

Eye (2004) 19, 382-386. doi:10.1038/sj.eye.6701512 Published online 13 August 2004

Keywords: diabetic macular oedema; intravitreal; triamcinolone acetonide; primary therapy

\section{Introduction}

Diabetic macular oedema is retinal thickening caused by the accumulation of intraretinal fluid, primarily in the inner and outer plexiform layers, resulting from hyperpermeability of the retinal vasculature. ${ }^{1}$ Macular oedema affects approximately $29 \%$ of diabetic patients with a disease duration of 20 years or more, and is responsible for a significant degree of visual loss in this population. ${ }^{1}$

The Early Treatment Diabetic Retinopathy Study (ETDRS) demonstrated a significant benefit of focal laser photocoagulation for the treatment of macular oedema. ${ }^{2}$ Although immediate focal photocoagulation reduced moderate visual loss by $50 \%, 12 \%$ of treated eyes still lost 15 or more ETDRS letters at the 3-year follow-up interval. ${ }^{2}$ In contrast, less than $3 \%$ of treated eyes showed an improvement of the same magnitude. Furthermore $24 \%$ of immediately treated eyes had thickening involving the centre of the macula at 36 months. ${ }^{2}$ Several studies evaluated grid-pattern laser photocoagulation for diabetic macular oedema; however, the treatment has limited efficacy and progressive enlargement of laser scar may occur. $^{3-6}$ The failure of laser photocoagulation in a substantial subgroup of patients has prompted interest in other treatment methods, including surgical treatment with pars plana vitrectomy and pharmacologic therapy with a sustainedrelease intravitreal corticosteroid implant. ${ }^{7-10}$ 
Intravitreal corticosteroids have also been tried experimentally in the prevention or treatment of proliferative vitreoretinopathy, retinal neovascularization and choroidal neovascularization. ${ }^{11-13}$ It was shown that intravitreal injection of triamcinolone acetonide treated effectively macular oedema secondary to diabetic retinopathy, chronic uveitis, central retinal vein occlusion and cataract surgery. ${ }^{10,14-19}$ The purpose of this study was to evaluate the use of intravitreal triamcinolone in eyes with diabetic macular oedema that had no previous laser treatment.

\section{Materials and methods}

In this clinical trial, 12 eyes of 12 patients with diabetic retinopathy (five men, seven women), aged 47-70 years (median 59. 2), were evaluated. The eligibility criteria for this study included: (1) the presence of clinically significant macular oedema in the fundus examination; (2) a history of angiographically confirmed diabetic macular oedema; (3) persistence of the macular oedema despite medical treatment with topical corticosteroids, topical nonsteroidal antiinflammatory agents, and systemic acetozolamide for at least 3 months; (4) no evidence of ocular disorders that might potentially result in macular oedema, such as uveitis, macular pucker or vitreo-macular traction; (5) no evidence of glaucoma or ocular hypertension. In this consecutive series, no eyes received previous laser photocoagulation.

The patients underwent complete ophthalmic examinations, including corrected visual acuity measurement (with ETDRS chart), slit lamp biomicroscopy, indirect ophthalmoscopy, colour fundus photography, fluorescein angiography and optical coherence tomography (OCT). Fluorescein angiograms were performed on a Heidelberg Scanning Laser Ophthalmoscope (Heidelberg Engineering, Heidelberg, Germany). OCT examinations were performed using the OCT 3000 scanner (Carl Zeiss Ophthalmic System Inc., Humphrey Division, Dublin, CA, USA). Fluorescein angiographic macular oedema was thought to be present if the typical oval or petaloid hyperfluorescent cystoid spaces radiating from the fovea were evident during fluorescein angiography. The OCT examination was thought to show macular oedema if there were hyporeflective intraretinal cavities radiating from the centre of the macula in cross-sectional scans.

Intravitreal injection of triamcinolone (Kenacort-A; $40 \mathrm{mg} / \mathrm{ml}$, Bristol-Myers Squibb Co, Princeton, NJ) was offered to treat macular oedema. Informed consent was obtained from each patient. Baseline parameters were
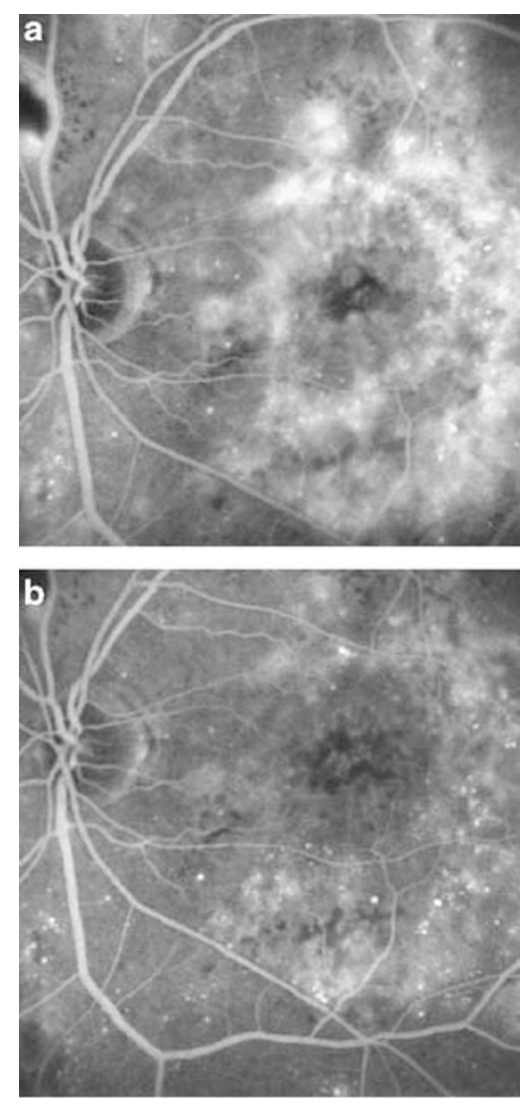

Figure 1 Case 6. (a) Pretreatment, fluorescein angiogram of the left eye demonstrating diabetic macular oedema. (b) Fluorescein angiogram of the same eye 6 months after treatment demonstrating disappearence of macular oedema.

included: visual acuity, OCT central macular thickness, and intraocular pressure (IOP).

Topical proparacaine hydrocholoride was applied to the ocular surface followed by preparation with 5\% povidone iodine. A cotton-tipped application soaked in proparacaine hydrocholoride was then applied to the injection site $4 \mathrm{~mm}$ posterior to the limbus. The injection consisted of $0.1 \mathrm{ml}(4 \mathrm{mg})$ of a commercially available suspension of triamcinolone acetonide. Indirect ophthalmoscopy was used to confirm proper intravitreal localization of the suspension. Patients were examined on days 1 and 7 to evaluate for infection.

The response to treatment was monitored functionally by visual acuity assessment and anatomically by OCT central macular thickness at 1-, 3- and 6-month intervals after injection. Potential corticosteroid-induced and injection-related complications were also observed. During follow-up according to the optical coherence tomography results, patients with recurrent macular oedema were retreated. 
Table 1 Pretreatment characteristics of the enrolled patients, follow-up periods, visual acuity and central macular thickness changes after treatment

\begin{tabular}{|c|c|c|c|c|c|c|c|c|c|c|c|}
\hline $\begin{array}{l}\text { Case } \\
\text { No }\end{array}$ & Age & $\begin{array}{c}\text { Duration } \\
\text { of } M E \\
(M o)\end{array}$ & $\begin{array}{l}\text { Follow-up } \\
(\mathrm{Mo})\end{array}$ & $\begin{array}{c}V A \\
\text { Initial } \\
\text { (letter) }\end{array}$ & $\begin{array}{c}V A \\
(1 \mathrm{Mo}) \\
\text { (letter) }\end{array}$ & $\begin{array}{c}V A \\
(3 \mathrm{Mo}) \\
\text { (letter) }\end{array}$ & $\begin{array}{c}V A \\
(6 \mathrm{Mo}) \\
(\text { letter })\end{array}$ & $\begin{array}{c}C M T \\
\text { (initial) } \\
(\mu m)\end{array}$ & $\begin{array}{c}\text { CMT } \\
(1 \mathrm{Mo}) \\
(\mu \mathrm{m})\end{array}$ & $\begin{array}{c}\text { CMT } \\
(3 \mathrm{Mo}) \\
(\mu \mathrm{m})\end{array}$ & $\begin{array}{c}\text { CMT } \\
(6 \mathrm{Mo}) \\
(\mu \mathrm{m})\end{array}$ \\
\hline 1 & 56 & 4 & 8 & $20 / 200$ & $20 / 160$ & $20 / 160$ & $20 / 160$ & 585 & 305 & 412 & 298 \\
\hline 2 & 58 & 3 & 6 & $20 / 200$ & $20 / 80$ & $20 / 80$ & $20 / 80$ & 348 & 218 & 223 & 245 \\
\hline 3 & 50 & 4 & 6 & $20 / 63$ & $20 / 50$ & $20 / 50$ & $20 / 50$ & 380 & 239 & 232 & 267 \\
\hline 4 & 47 & 3 & 8 & $20 / 125$ & $20 / 125$ & $20 / 125$ & $20 / 125$ & 465 & 310 & 361 & 352 \\
\hline 5 & 70 & 5 & 8 & $20 / 200$ & $20 / 160$ & $20 / 160$ & $20 / 160$ & 680 & 323 & 352 & 394 \\
\hline 6 & 63 & 3 & 9 & $20 / 80$ & $20 / 32$ & $20 / 32$ & $20 / 32$ & 486 & 265 & 252 & 365 \\
\hline 7 & 60 & 3 & 7 & $20 / 200$ & $20 / 125$ & $20 / 200$ & $20 / 125$ & 565 & 234 & 462 & 301 \\
\hline 8 & 54 & 3 & 6 & $20 / 100$ & $20 / 32$ & $20 / 32$ & $20 / 32$ & 318 & 214 & 205 & 238 \\
\hline 9 & 57 & 4 & 10 & $20 / 80$ & $20 / 40$ & $20 / 40$ & $20 / 40$ & 305 & 252 & 234 & 283 \\
\hline 10 & 62 & 4 & 10 & $20 / 160$ & $20 / 160$ & $20 / 160$ & $20 / 160$ & 344 & 293 & 340 & 267 \\
\hline 11 & 69 & 3 & 8 & $20 / 125$ & $20 / 100$ & $20 / 125$ & $20 / 100$ & 390 & 217 & 236 & 219 \\
\hline 12 & 65 & 4 & 9 & $20 / 200$ & $20 / 160$ & $20 / 160$ & $20 / 125$ & 518 & 315 & 411 & 305 \\
\hline
\end{tabular}

$\mathrm{ME}=$ macular oedema, $\mathrm{Mo}=$ month, $\mathrm{CMT}=$ central macular thickness, $\mathrm{VA}=$ visual acuity.

\section{Results}

Pretreatment clinical characteristics of the enrolled eyes are summarized in Table 1. The follow-up period was between 6 and 10 months (mean 7.9 months) and all the eyes completed 6 months of follow-up. Macular oedema was documented for a median of 3.5 months ( 3-5 months) before intravitreal corticosteroid injection. Before intravitreal triamcinolone injection, all the eyes had been treated with oral and topical nonsteroidal antiinflammatory drugs, topical steroids and oral acetazolamide.

Baseline mean central macular thickness was $448.6 \mu \mathrm{m}$. At 1 month follow-up, a reduction in mean central macular thickness of $40.8 \%$ from 448.6 to $265.4 \mu$ m was obtained. No patient had recurrent macular oedema at this examination. At 3 and 6 months follow-up, mean central macular thickness was 310 and $294.5 \mu \mathrm{m}$, respectively. At 3 months follow-up, central macular thickness had increased in eight eyes (66.6\%) when compared with 1 month results. At 6 months follow-up, central macular thickness had increased in seven eyes (58.3\%) when compared with 3 month results. At 3 months examination six patients $(50 \%)$ (cases 1, 4, 5, 7, 10, $12)$; at 6 months examination five patients $(41.6 \%)$ (cases $4,5,6,9,12)$ had recurrent macular oedema and retreatment was performed in these patients. Fluorescein angiogram and optical coherence tomography of case 6, before and 6 months after treatment were shown in Figures 1 and 2.

No eyes lost vision at 1 month and 10 eyes (83.2\%) showed improvement. At 3 months no eyes lost vision from baseline and eight eyes $(66.6 \%)$ showed improvement. At 6 months, again no eyes lost vision from baseline and 10 eyes $(83.2 \%)$ maintained improved visual acuity. In all, six (60\%) of these 10 eyes maintained
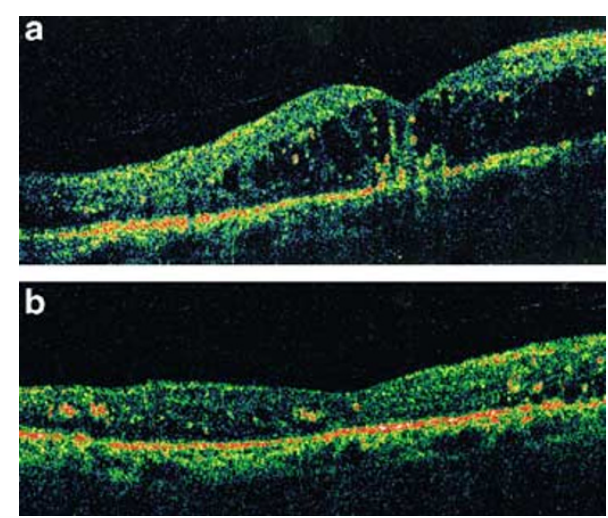

Figure 2 Case 6. Optical coherence tomography of the left macula, showing the resolution of diabetic macular oedema. (a) Pretreatment, central macular thickness was $486 \mu \mathrm{m}$; (b), 6 months after treatment, central macular thickness was $275 \mu \mathrm{m}$.

a visual gain of 20/100 or more at 6 months. Cases 4 and 10 showed no visual acuity changes during follow-up.

At 1 month examination, the average IOP measurement rose from 14.7 to $19.1 \mathrm{mmHg}$. At 3 and 6 months, the average IOP measurements were 17.9 and 16.8 , respectively. Three eyes $(25 \%)$ (cases $2,5,8)$ exhibiting IOP elevation higher than $21 \mathrm{mmHg}$ on a given examination were controlled on the subsequent examination with a $\beta$-blocker medication. No cataract progression, endophthalmitis and injection-related complications were encountered.

\section{Discussion}

Diabetic macular oedema is one of the most frequent causes for a major loss of vision in patients with diabetes mellitus. ${ }^{1}$ The exact pathogenesis of diabetic macular oedema has not been elucidated, although a breakdown 
of the inner blood-retinal barrier is generally accepted. ${ }^{20}$ In addition, both clinical observations and studies involving diabetic animal models have implicated breakdown of the outer blood-retinal barrier in the development of diabetic macular oedema. ${ }^{21,22}$ Some studies suggest that vitreo-macular traction may play a role in increased retinal vascular permeability. ${ }^{23,24}$ So, pars plana vitrectomy has been advocated for the treatment of macular oedema with or without a taut, attached posterior hyaloid. ${ }^{7-9}$

Corticosteroids have long been used in the treatment of cystoid macular oedema because of their ability to inhibit the arachinoid acid pathway. Corticosteroids may also downregulate the production of vascular endothelial growth factor, a known vascular permeability factor. ${ }^{25}$ Intravitreal corticosteroids have been tried experimentally in the prevention or treatment of proliferative vitreoretinopathy, retinal neovascularization, and choroidal neovascularization. ${ }^{11-}$ ${ }^{13}$ The rationale for intravitreal corticosteroids parallels that established for other routes of corticosteroid administration, specifically the anti-inflammatory effect. However, the intravitreal route alleviates the pharmacologic issues of penetration and bioavailability. A potent dose of medication is delivered directly to its site of action with rapid onset.

Previous studies show that intravitreal tramcinolone is a promising therapeutic method for diabetic macular oedema that fails to respond to conventional laser photocoagulation. ${ }^{10,14,26}$ It is well known that diabetic macular oedema carries a particularly poor prognosis despite laser photocoagulation. ${ }^{2}$ Furthermore, laser coagulation of the macular region often does not lead to an increase of vision, and it irreversibly destroys valuable retinal tissues. ${ }^{27}$

In our small series the efficacy of intravitreal triamcinolone in patients with diabetic macular oedema that had no previous laser treatment was evaluated. The results of the present study confirm previous reports showing that the intravitreal application of crystalline cortisone can increase visual acuity in patients with diffuse diabetic macular oedema. ${ }^{10,26}$ All patients in this series showed an increase in visual acuity compared to the baseline of the study. Parallel to the increase in visual acuity, central macular thickness decreased significantly. The decrease in central macular thickness in patients of the present study was not constant for the whole followup period of the study. At 3 months follow-up, central macular thickness had increased in $66.6 \%$ of patients when compared with the 1 month results. At 6 months follow-up, central macular thickness had increased in $58.3 \%$ of patients when compared with the 3 month results. Compared with baseline values however, visual acuity measurements taken 3 and 6 months after the triamcinolone acetonide injection were still higher.

Our results show that intravitreal triamcinolone is an effective therapeutic method in diabetic macular oedema that had no previous laser treatment. When intravitreal triamcinolone is applied as a primary therapy in diabetic macular oedema functional and anatomical improvements can be obtained without irreversible changes in the macular region. Further study with longer follow-up and large series is warranted to assess the long-term efficacy and safety and the need for retreatment.

\section{References}

1 Klein R, Klein BE, Moss SE, David MD, De Mets DL. The Wisconsin Epidemiologic study of Diabetic Retinopathy IV. Diabetic macular oedema. Ophthalmology 1984; 91: 1464-1474.

2 Photocoagulation for diabetic macular oedema. Early treatment diabetic retinopathy study report number 1. Early treatment diabetic retinopathy study research group. Arch Ophthalmol 1985; 103: 1796-1806.

3 Blankenship GW. Diabetic macular oedema and argon laser photocoagulation. A prospective randomized study. Ophthalmology 1979; 86: 69-75.

4 McDonald HR, Schatz H. Grid photocoagulation of diffuse macular oedema. Retina 1985; 5: 65-72.

5 Olk RJ. Modified grid argon (blue-green) laser photocoagulation for diffuse macular oedema. Ophthalmology 1986; 93: 938-948.

6 Schatz H, Maderia D, Johnson RN. Progressive enlargement of laser scars following grid laser photocoagulation for diffuse diabetic macular oedema. Arch Ophthalmol 1991; 109: 1549-1551.

7 Harbour JW, Smiddy WE, Flynn Jr HW, Rubsamen PE. Vitrectomy for diabetic macular oedema associated with a thickened and taut posterior hyaloid membrane. Am J Ophthalmol 1996; 121: 405-413.

8 Ikeda T, Sato S, Katano T, Hayashi Y. Vitrectomy for cystoid macular ooedema with attached posterior hyaloid membrane in patients with diabetes. Br J Ophthalmol 1999; 83: 12-14.

9 Pendergast SD, Hassan TS, Williams GA, Cox MS, Margherio RR, Ferrone PJ et al. Vitrectomy for diffuse diabetic macular oedema associated with a taut premacular posterior hyaloid. Am J Ophthalmol 2000; 130: 178-186.

10 Martidis A, Duker JS, Greenberg PB, Rogers AH, Puliafito CA, Reichel E et al. Intravitreal triamcinolone for refractory diabetic macular oedema. Ophthalmology 2002; 109: 920-927.

11 Jonas JB, Hayler JK, Panda-Jonas S. Intravitreal injection of crystalline cortisone as adjunctive treatment of proliferative vitreoretinopathy. Br J Ophthalmol 2000; 84: 1064-1067.

12 Danis RP, Bingaman DP, Yang Y, Ladd B. Inhibition of preretinal and optic nerve head neovascularization in pigs by intravitreal triamcinolone acetonide. Ophthalmology 1996; 103: 2099-2104.

13 Danis RP, Ciulla TA, Pratt LM, Anliker W. Intravitreal triamcinolone acetonide in exudative age-related macular degeneration. Retina 2000; 20: 244-250. 
14 Jonas JB, Söfker A. Intraocular injection of crystalline cortisone as adjunctive treatment of diabetic macular oedema. Am J Ophthalmol 2001; 132: 425-427.

15 Degenring RF, Jonas JB. Intravitreal injection of triamcinolone acetonide as a treatment for chronic uveitis. Br J Ophthalmol 2003; 87: 361.

16 Benhamou N, Massin P, Haouchine B, Audren F, Tadayoni R, Gaudic A. Intravitreal triamcinolone for refractory pseudofakic macular oedema. Am J Ophthalmol 2003; 135: 246-249.

17 Conway MD, Canakis C, Livir-Rallatos C, Peyman GA. Intravitreal triamcinolone acetonide for refractory chronic pseudofakik cystoid macular oedema. J Cataract Refract Surg 2003; 29: 27-33.

18 Greenberg PB, Martidis A, Rogers AH, Duker JS, Reichel E. Intravitreal triamcinolone acetonide for macular oedema due to central retinal vein occlusion. Br J Ophthalmol 2002; 86: 247-248.

19 Jonas JB, Kreissig I, Degenring RF. Intravitreal triamcinolone acetonide as a treatment of macular oedema in central retinal vein occlusion. Graefes Arch Clin Exp Ophthalmol 2002; 240: 782-783.

20 Shatz H, Patz A. Cystoid maculopathy in diabetics. Arch Ophthalmol 1976; 94: 761-768.

21 Krupin T, Waltman SR, Szewczyk P et al. Fluorometric studies on the blood-retinal barrier in experimental animals. Arch Ophthalmol 1982; 100: 631-634.
22 Kimber WM, Nichols CW, Grimes PA, Winegrad AI, Laties AM. A permeability defect of the retinal pigment epithelium: occurence in early streptozocin diabetes. Arch Ophthalmol 1980; 98: 725-728.

23 Schepens CL, Avila MP, Jalkh AE, Trempe CL. Role of the vitreous in cystoid macular oedema. Surv Ophthalmol 1984; 28: 499-504.

24 Nasrallah FP, Jalkh AE, Van Coppenolle F, Kado M, Trempe CL, McMeel JW et al. The role of the vitreous in diabetic macular oedema. Ophthalmology 1988; 95: 1335-1339.

25 Wilson CA, Berkowitz BA, Sato Y, Ando N, Handa JT, de Juan E Jr. Treatment with intravitreal steroid reduces blood-retinal barrier breakdown due to retinal photocoagulation. Arch Ophthalmol 1992; 110: 1155-1159.

26 Jonas JB, Kreissig I, Sofker A, Degnring RF. Intravitreal injection of triamcinolone for diffuse diabetic macular oedema. Arch Ophthalmol 2003; 121: 57-61.

27 Early Treatment Diabetic Retinopathy Study Research Group. Focal photocoagulation treatment of diabetic macular oedema Relationship of treatment effect to fluorescein angiographic and other retinal characteristics at baseline: ETDRS report no.19. Arch Ophthalmol 1995; 113: 1144-1155. 